ECCOMAS Proceedia
COMPDYN 2021

$8^{\text {th }}$ ECCOMAS Thematic Conference on Computational Methods in Structural Dynamics and Earthquake Engineering M. Papadrakakis, M. Fragiadakis (eds.) Streamed from Athens, Greece, 28 - 30 June 2021

\title{
A SIMPLIFIED APPROACH FOR THE ESTIMATION OF SEISMIC VULNERABILITY OF STEEL MOMENT RESISTING FRAMES
}

\author{
Rosario Montuori ${ }^{1}$, Elide Nastri ${ }^{2}$, Vincenzo Piluso ${ }^{2}$, Paolo Todisco ${ }^{2, *}$ \\ ${ }^{1}$ University of Salerno, Department of Pharmacy \\ Via Giovanni Paolo II, 132, 84084 Fisciano (SA) \\ e-mail: r.montuori@unisa.it \\ ${ }^{2}$ University of Salerno, Department of Civil Engineering \\ Via Giovanni Paolo II, 132, 84084 Fisciano (SA) \\ \{enastri,v.piluso,ptodisco\}@unisa.it
}

\begin{abstract}
In recent years, the numerous seismic events occurred have pointed out the need for a prompt classification of the built heritage in terms of seismic vulnerability. the concept of vulnerability is closely linked to the definition of the capacity curve, requiring sophisticated numerical procedures to be perferomed, such as the inelastic incremental analysis.

Therefore, the simplified method herein proposed requires use of only analytically simple analyses such as the elastic analysis and the rigid-plastic analysis. For this reason, this method can be used in the immediate aftermath of an earthquake and also for a large-scale classification of the buildings. The proposed methodology has been set up by a wide parametric analysis, carried out on 420 frames designed according to 3 different approaches: the first one is linked to the Theory of Plastic Mechanism Control (TPMC), assuring the design of structures showing global collapse mechanism (GMRFs), the second is based on the Eurocode 8 requirements (SMRFs) while the third is a non-seismic design, based on vertical loads (OMRFs).
\end{abstract}

Keywords: Pushovers, Capacity, Performances, Vulnerability, Simplified methods. 


\section{INTRODUCTION}

The evaluation of seismic performances of existing buildings has gained, in recent years, an increasingly interest in seismic and structural engineering [1]-[11]. In particular, the setting up of design rules based on the so-called hierarchy criteria has changed the designer approach to let building able to withstand seismic events with an adequate level of reliability [12]-[22]. In the safeguard of the built heritage the knowledge of the seismic response of the structures plays a fundamental role [24]-[25]. Therefore, any seismic retrofitting or improvement of an existing building should be preceded by a strength evaluation phase before the intervention. The evolution of codes, numerical methods and calculation tools has provided designers the access to advanced methodologies of seismic assessment [26]. The seismic performances of buildings are evaluated by comparing the capacity of dissipating incoming seismic energy with the seismic demand. The main difficulties that arise from developing a performance checking procedure, are linked to the definition of damage levels corresponding to predetermined performance levels, in a methodology that can be applied in everyday practice [27]-[30]. Resorting to nonlinear static analysis, through a structural analysis programme, is conditioned by the precision of the structural model, having to be adequately accurate to catch the non-linear behaviour. The whole process is not easy to standardise and for this reason a simplified methodology, able to define the capacity curve analytically, has been defined. This model shows a full inclination to code liability not requiring complicated analyses and being uniquely defined. To this scope, several parametric analyses, in terms of pushover, on 420 frames, designed according to three different approaches, were made and their results in terms of capacity curves were analysed. In particular, each capacity curve has been simplified by defining 3 branches: the elastic response curve, the maximum horizontal forces multiplier curve and the mechanism equilibrium curve. In this evaluation, the role of the beam-to-column joints has not been considered considering that the beam ends are equipped with full strength-full stiff joints [31]-[38].

\section{TRILINEAR MODEL OF THE CAPACITY CURVE}

\subsection{Definition of the three branches}

One of the most common tools adopted to assess the capacity of a structure is the pushover analysis. The simplified method herein proposed only requires use of common analyses such as the elastic structural analysis and the rigid-plastic analysis. For this reason, it lends itself well to be used in the immediate aftermath of an earthquake, not requiring any static or dynamic non-linear analyses. Therefore, the user can quickly obtain the capacity curve through the intersection of three linear branches (Fig. 1), computed by means of simple equations reported in the following. The shape of the capacity curve, for a given structure, is affected by the occurring collapse mechanism. The first branch is affected by the elastic behavior of the structure. The knee depends on the plastic capacity distribution, appearing sharper as more as the plastic hinges develop simultaneously while the slope of softening branch is linked to the second-order effects.

Referring to the trilinear model proposed, the first branch of the curve can be approximated by the elastic response curve; the horizontal one is provided by the maximum load bearing capacity, while, the softening branch is given by the collapse mechanism equilibrium curve of the structure, influenced by the second order effects. The definition of the third branch, is linked to the concept of mechanism equilibrium curve [40], [41]. Therefore, the mechanism equilibrium curve is a straight line, expressed in the following form:

$$
\alpha=\alpha_{0}-\gamma_{s} \delta
$$




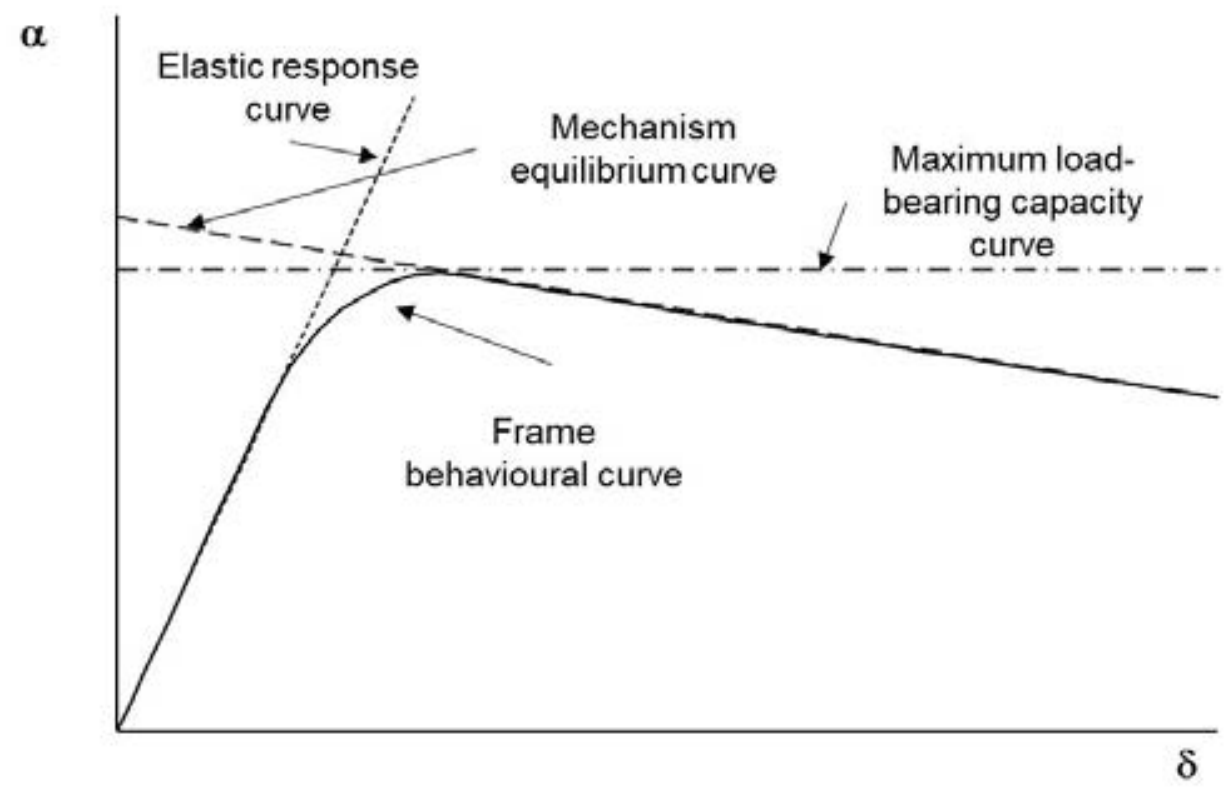

Figure 1: Trilinear model of the capacity curve.

where $\alpha_{0}$ is the kinematically admissible multiplier of horizontal forces due to first-order rigidplastic analysis and $\gamma_{s}$ is the slope of the mechanism equilibrium curve [42]-[51]. Providing input data about mechanical and geometric properties of structural members, acting forces [52][54] and the potential collapse configurations, both $\alpha_{0}$ and $\gamma_{s}$ can be computed for each type of possible collapse mechanism. According to the extension of the kinematic theorem of plastic collapse to the concept of mechanism equilibrium curve, the triggering mechanism will be the one characterized by the curve located below the others into a given displacement range compatible with the local ductility supply.

\subsection{Parametric analysis}

The definition of the horizontal branch of the trilinear curve and the plastic rotation demand corresponding to the collapse condition was achieved through a wide parametric analysis on moment resisting steel frames (MRFs) and calibrated by regression analysis according to the results obtained by the pushovers performed on MRFs.

The parametric analysis has been carried out with reference to three categories of frames:

- GMRFs (Global moment resisting frames) designed according to TPMC procedure (showing global collapse mechanisms);

- SMRFs (Special moment resisting frames) designed according to hierarchy criterion as suggested by Eurocode 8 [53], able to avoid "soft storey" collapse mechanisms;

- OMRFs (Ordinary moment resisting frames) designed without any requirement aimed at the control of the collapse mechanism and usually showing "soft storey" collapse mechanism.

The parametric analysis regarded 140 geometrical schemes of low-rise frames by varying the number of bays, $n_{b}$ from 2 to 6 , the number of storeys, $n_{s}$ from 2 to 8 , the bay span, equal to $3,00 \mathrm{~m}, 4.50 \mathrm{~m}, 6.00 \mathrm{~m}, 7.50 \mathrm{~m}$ and the three different design approaches for a total number of 
420 designed structures. All the combinations were analysed considering dead loads $\left(G_{k}\right)$ equal to $3.5 \mathrm{kN} / \mathrm{m}^{2}$, live loads $\left(Q_{k}\right)$ equal to $3 \mathrm{kN} / \mathrm{m}^{2}$ and interstorey height of $3.5 \mathrm{~m}$ [54].

\subsection{Calibration of maximum multiplier formula}

To define the horizontal branch of the trilinear curve and the point corresponding to the collapse condition, wide parametric and regression analyses on moment resisting steel frames (MRFs) have been carried out. In particular, MRFs are analysed through pushover analyses [56] in order to check the correspondence between their results and the aforementioned trilinear model. The maximum multiplier corresponding to the maximum bearing capacity is derived by the Merchant-Rankine formula [57] as a combination of the collapse multiplier obtained by the rigid-plastic analysis $\alpha_{0}$ and the critical collapse multiplier for vertical loads. Introducing a calibration factor, useful to ensure a large application of the method, the relation has been rearranged as:

$$
\alpha=\alpha_{0}-\gamma_{s} \delta
$$

where:

$$
\begin{aligned}
& \alpha=\alpha_{0}-\gamma_{s} \delta \\
& \alpha=\alpha_{0}-\gamma_{s} \delta
\end{aligned}
$$

$I_{b}$ and $L_{b}$ are the inertia and the length of the beam, respectively; $I_{c}$ e $L_{c}$ are the inertia and the height of the column; $E$ is the elastic modulus; $a$ and $b$ are the regression coefficients. The parameter $\xi$ is calculated with reference to the first storey members.

The coefficient $\Psi$ can be computed according to the following relation, which guarantees an accurate evaluation of the $\alpha_{\max }$ as Figure 2 testifies:

$$
\alpha=\alpha_{0}-\gamma_{s} \delta
$$

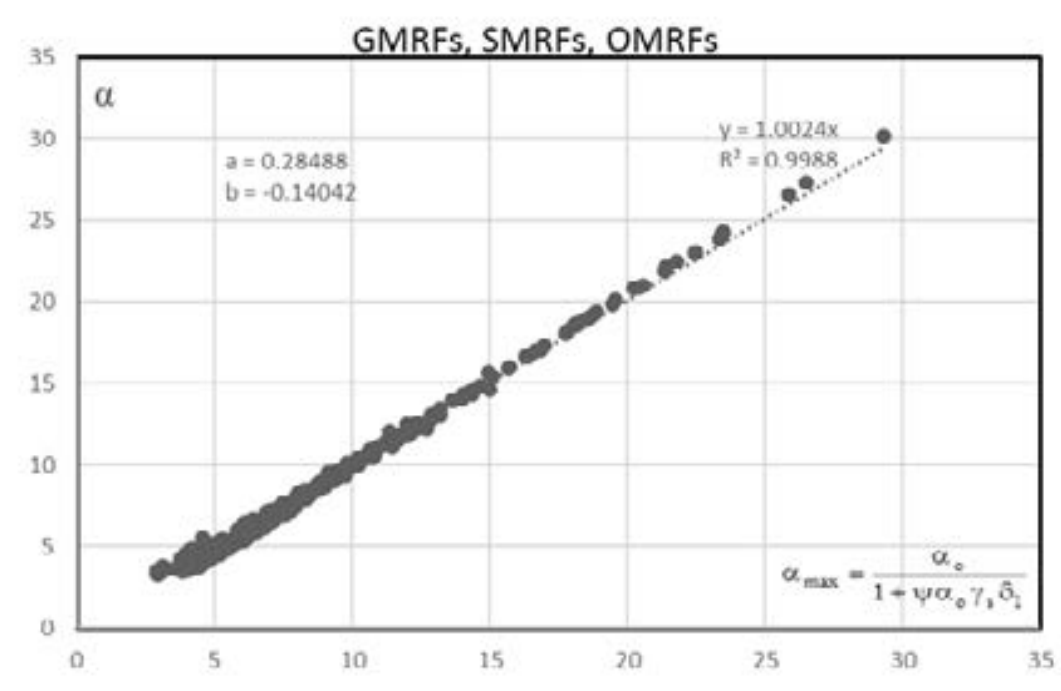

Figure 2: Regression analysis for the maximum multiplier formula. 


\subsection{Characteristic points of the trilinear model}

Starting from the trilinear approximation model, four characteristic points of the simplified capacity curve (points A, B, C, D of Fig. (3)) have been identified. These points are associated to limit states with the meaning of identifying a target performance [58]-[61].

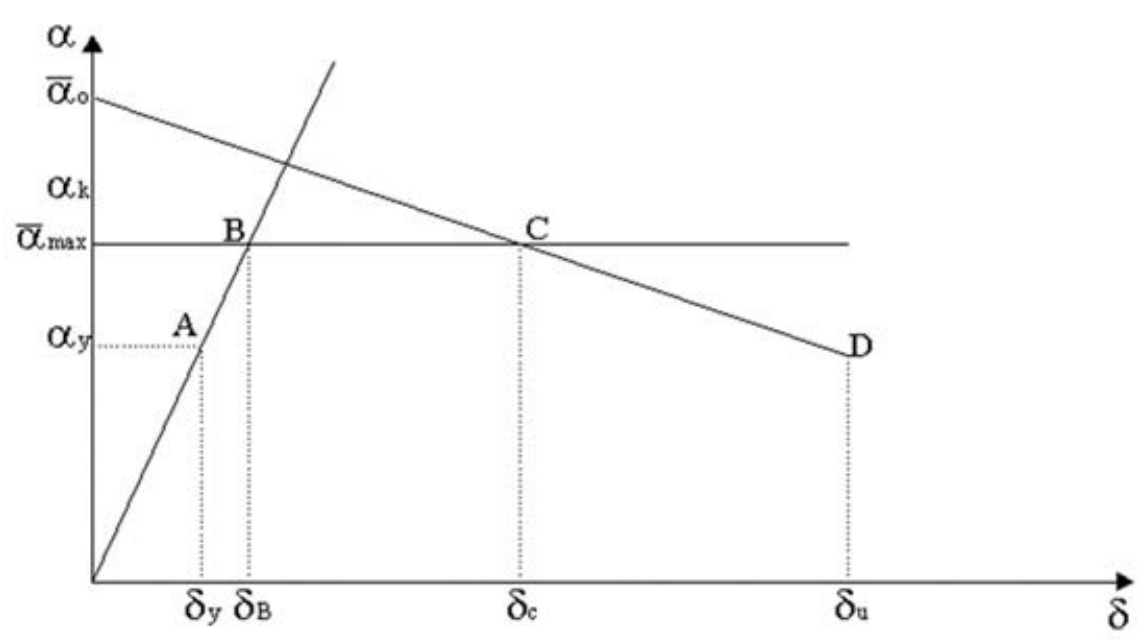

Figure 3: Characteristic points of the trilinear capacity curve

- Point A

This point corresponds to the minimum value between the maximum storey displacement under serviceability conditions and the multiplier of the horizontal forces corresponding to the formation of the first plastic hinge. It is associated with the "Fully Operational" limit state.

The multiplier corresponding to point A, will be calculated as follows:

$$
\alpha=\alpha_{0}-\gamma_{s} \delta
$$

- Point B

Point B corresponds to the development of the maximum bearing capacity of the structure and to the elastic limit of the structure and is associated with the "Operational" limit state. To locate point $\mathrm{B}$, the maximum multiplier $\left(\alpha_{\max }=\alpha_{B}\right)$ has to be computed, by means of the MerchantRankine formula (Eq. (2)).

Therefore, it can be stated that:

$$
\alpha_{\max }=\alpha_{B}=\frac{1}{\delta_{1}} \delta_{B}
$$

where the unknown is the top sway displacement $\delta_{B}$

\section{- Point $C$}

Point $\mathrm{C}$ corresponds to the development of the collapse mechanism and is associated with the "Life Safety" limit state.

The corresponding top sway displacement $\delta_{C}$ can be derived as follows:

$$
\delta_{C}=\delta_{\text {mecc }}=\frac{\alpha_{0}-\alpha_{\max }}{\gamma_{s}}+\delta_{y}
$$

- Point $D$ 
Point D corresponds to the overcoming, at least in one member, of the local ductility supplies and is associated with the "Near Collapse" limit state. This is the case of very rare seismic events in which considerable local ductility is required.

The corresponding top sway displacement $\delta_{D}=\delta_{u}$, is calculated as follows:

$$
\delta_{D}=\delta_{C}+\left(\vartheta_{p . u}-\vartheta_{p . m e c c}\right) H_{0}
$$

where $\vartheta_{p . u}$ is the plastic hinge rotation assumed equal to $8.0 \vartheta_{y}$ according to Eurocode 8 [60], $\vartheta_{\text {p.mecc }}$ is the plastic hinge rotation corresponding to the formation of the collapse mechanism, $H_{0}$ is the total height of storeys involved into the collapse mechanism.

For the evaluation of plastic rotations occurring in the critical members, an analytical formulation is proposed, based on a simplified Grinter's (shear type) single storey portal in which it is assumed that the plastic moments are different at the top and at the base of the columns, to represent the plastic redistribution capacity characterizing frames with more storeys and bays. The relationships for the evaluation of the plastic rotation corresponding to the development of the collapse mechanism are proposed as follows:

$$
\begin{gathered}
\frac{\theta_{p . m e c} H_{0}}{n_{S} \delta_{y}}=\frac{\Psi_{1}}{\Psi_{2}} \Psi_{3}\left(\frac{\alpha_{\max }}{\alpha_{y}}-1\right)^{\Psi_{4}} \frac{1-\Psi_{5} \gamma_{s}}{1-\Psi_{6} \gamma_{s}} \\
\frac{\theta_{p . m e c} H_{0}}{n_{s} \delta_{y}}=\frac{\Psi \prime_{1}}{\Psi \prime_{2}} \Psi_{3}\left(\frac{\alpha_{\max }}{\alpha_{y}}-1\right)^{\Psi \prime_{4}} \frac{1-\Psi_{5} \gamma_{S}}{1-\Psi \prime_{6} \gamma_{s}}
\end{gathered}
$$

where $H_{0}$ is the total height of storeys involved into the collapse mechanism, $n_{s}$ is the number of storeys, $\alpha_{y}$ is the multiplier of the horizontal forces corresponding to the formation of the first plastic hinge, $\delta_{y}$ is the displacement corresponding to the formation of the first plastic hinge. The $\Psi_{i}$ coefficients, determined by regression analyses, are given by:

$$
\begin{array}{ccc}
\Psi_{1}=a_{1}+b_{1} n_{b} & \Psi_{1}^{\prime}=a_{1}^{\prime}+b_{1}^{\prime} n_{b} \\
\Psi_{2}=a_{2}+b_{2} n_{s} & \Psi_{2}^{\prime}=a_{2}^{\prime}+b_{2}^{\prime} n_{s} \\
\Psi_{i}=a_{i}+b_{i} \xi i=3, \ldots, 6 & \Psi^{\prime}{ }_{i}=a_{i}^{\prime}+b_{i}^{\prime} \xi i=3, \ldots, 6
\end{array}
$$

The results of linear regression on GMRFs and SMRFs, are reported in Figs. (4-7).

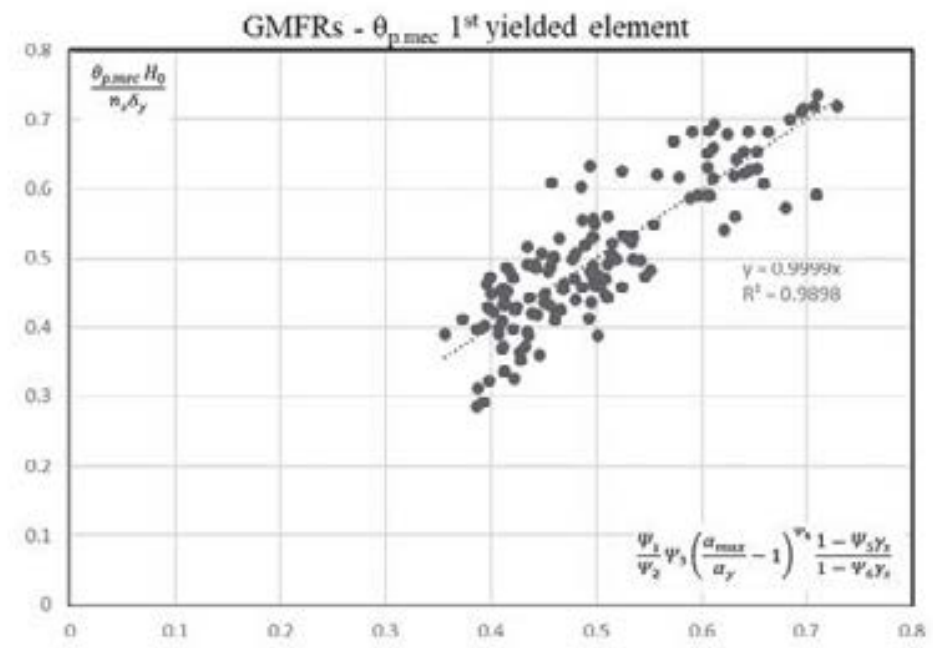

Figure 4: Regression analysis GMRFs - $\theta_{\mathrm{p} . \mathrm{mec}}, 1^{\text {st }}$ yielded element. 


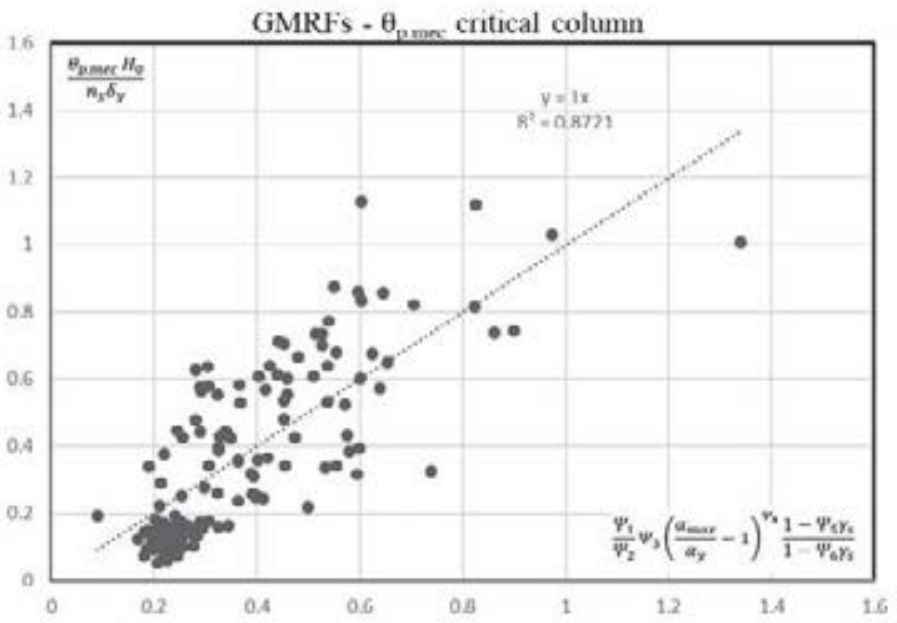

Figure 5: Regression analysis GMRFs - $\theta_{\text {p.mec }}$, critical column.

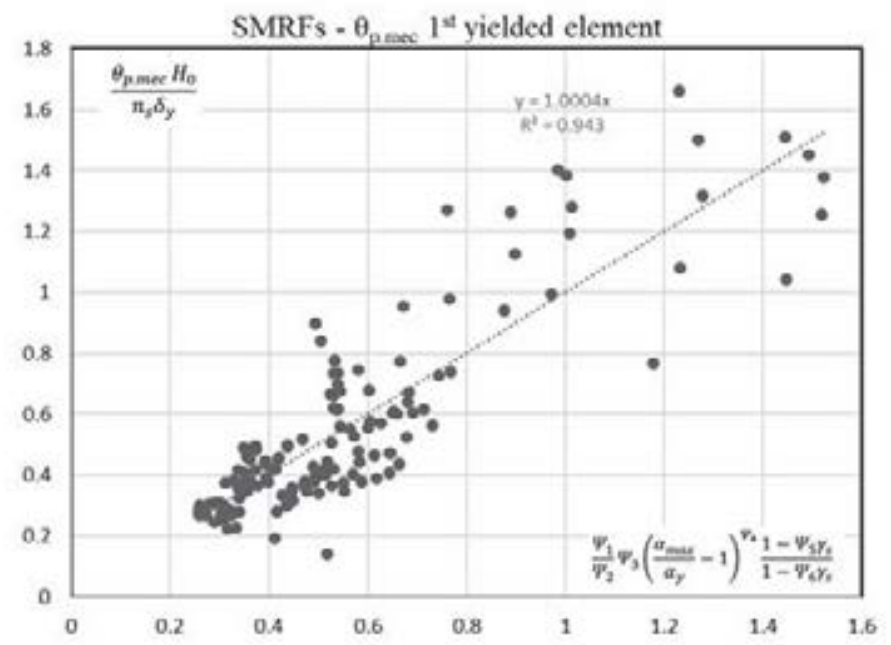

Figure 6: Regression analysis SMRFs - $\theta_{\mathrm{p} . \mathrm{mec}}, 1^{\text {st }}$ yielded element.

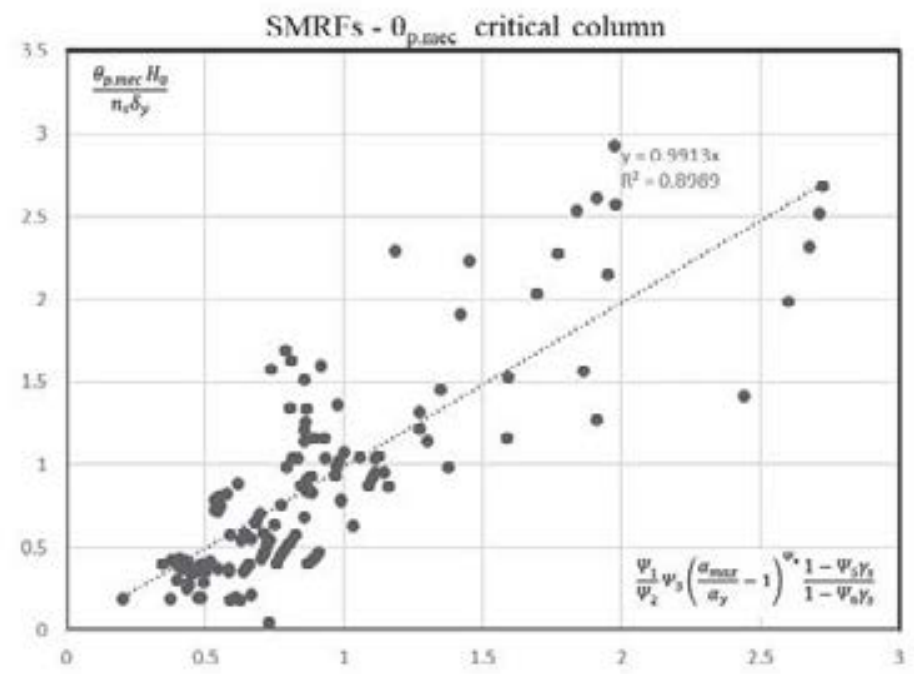

Figure 7: Regression analysis SMRFs - $\theta_{\text {p.mec }}$, critical column. 


\section{ASSESSMENT PROCEDURES IN TERMS OF SPECTRAL ACCELERATIONS}

\subsection{ADRS spectrum approach}

According to the ADRS spectrum approach, for each limit state, the spectrum $S_{a}-S_{D e}$ will be be defined by means of the relationship $S_{D e}(T)=S_{a}(T)(T / 2 \pi)^{2}$. For the definition of the capacity it is necessary to represent the characteristic points of the trilinear curve of the structure, in the ADRS plane through the abscissa, that is the displacement $d_{L S}^{*}=d_{L S} / \Gamma$.

It is necessary to distinguish between the cases $\mathrm{T}^{*}>\mathrm{T}_{\mathrm{C}}$ e $T^{*}<T_{C}$. If $\mathrm{T}^{*}>\mathrm{T}_{\mathrm{C}}$. The capacity in terms of spectral acceleration, for a specific limit state, can be obtained through the following relationship:

$$
S_{a S L}=d_{L S}^{*} \omega_{0}^{* 2}
$$

The demand is represented by the spectral acceleration provided by the code, for the specific limit state, considering the equivalent period of vibration $\mathrm{T}^{*}$.

For the assessment procedure, the inequality $S_{a l s} \geq S_{a}\left(T^{*}\right)$ has to be satisfied.

If $T^{*}<T_{C}$ and $\mathrm{q}>1$, according to equality of energy criteria, there is a different procedure to evaluate the capacity that leads to the anelastic spectrum:

$$
\begin{gathered}
F_{l s}^{*}=\frac{m^{*} S_{a}\left(T^{*}\right)}{q_{l s}} \\
q_{l s}=1+\left(\mu_{l s}-1\right) \frac{T^{*}}{T_{C}} \\
S_{a S L}=q_{l s} \frac{F_{l s}^{*}}{m^{*}}
\end{gathered}
$$

\subsection{Nassar \& Krawinkler approach}

The proposed approach overcomes the limits of the verification methodology proposed by the current seismic codes. In addition, it accounts for second-order effects, occurring when the collapse mechanism is fully developed.

In the framework of capacity-demand checking procedure, the MDOF actual system is replaced by an equivalent SDOF system an equivalent SDOF system introducing the modal participation factor $\Gamma$. Multiplying the multiplier of horizontal forces $\alpha$ with the design base shear the capacity curve is reported in a $F_{b}-d_{c}$ plane (base shear force-top-sway displacement).

The capacity curve must be reduced through the modal participation factor and represented in a $F^{*}-d^{*}$ plane through the relations $F^{*}=F_{b} / \Gamma, d^{*}=d_{c} / \Gamma$.

The demand can be estimated through the period $T^{*}$ and the equivalent mass $m^{*}$. In the following, the verification procedure for each characteristic point of the capacity curve approximated with trilinear model is reported.

- Point A (Fully operational)

The capacity in terms of spectral acceleration for the point $\mathrm{A}$ is given as follows:

$$
F_{F O}^{*}=m^{*} S_{a F O}\left(T^{*}\right)
$$

- Point B (Operational)

The capacity in terms of spectral acceleration for the point B is given as follows: 


$$
S_{a O}\left(T^{*}\right)=\frac{F_{O}^{*}}{m^{*}}
$$

- Point C (Life Safe)

The capacity in terms of spectral acceleration for the point $\mathrm{C}$ is given as follows:

$$
\begin{gathered}
S_{a L S}\left(T^{*}\right)=\frac{F_{L S}^{*}}{m^{*}} q_{L S} \\
q_{L S}=q_{0}\left(\mu, T, \gamma_{=0}\right)=\left[c\left(\mu_{L S}-1\right)+1\right]^{1 / c}
\end{gathered}
$$

where $c=\frac{T^{*}}{1+T^{*}}+\frac{0.42}{T^{*}}$ and $\mu_{L S}=\frac{d_{L S}{ }^{*}}{d_{O}{ }^{*}}$.

In the case of point $\mathrm{C}$ (and point $\mathrm{D}$ ), the structure draws on its own plastic resources to dissipate incoming seismic energy. Consequently, the q structure factor comes into play, expressed according to the formulation of Nassar and Krawinkler [30], as a function of the ductility $\mu_{L S}$.

- Point D (Near Collapse)

The capacity in terms of spectral acceleration for the point $\mathrm{D}$ is given as follows:

$$
\begin{aligned}
S_{a N C}\left(T^{*}\right) & =\frac{F_{N C}^{*}}{m^{*}} q_{N C} \\
q_{N C} & =\frac{q_{0}}{\varphi}
\end{aligned}
$$

To take these into account, the coefficient $\varphi$ which is a function of the ductility $\mu$ and the slope of the equilibrium curve $\gamma$ (expressing the sensitivity of the structure to second-order effects), has been introduced:

$$
\begin{gathered}
q_{0}\left(\mu, T, \gamma_{=0}\right)=\left[c\left(\mu_{N C}-1\right)+1\right]^{1 / c} \\
\text { where } c=\frac{T^{*}}{1+T^{*}}+\frac{0.42}{T^{*}} \text { and } \mu_{N C}=\frac{d_{N C^{*}}}{d_{O}{ }^{*}} \\
\varphi=\frac{1+0.62\left(\mu_{N C}-1\right)^{1.45} \gamma}{(1-\gamma)}
\end{gathered}
$$

\section{CONCLUSIONS}

In conclusion, the proposed methodology opens-up new scenarios regarding the seismic classification of the built heritage. An analytical methodology allows to evaluate uniquely the seismic vulnerability of buildings without passing through complex analyses not manageable by means of codes and prescriptions. The trilinear model seems to be the right compromise between accuracy in analysis and computational speed and fits well in all the major seismic codes. The assessment of structure performances, in terms of comparison capacity-demand, has been performed by means of the Nassar \& Krawinkler approach, characterized by a wide generality because it does not discriminate between high and low periods of vibration and accounts for second-order effects by means of the stability coefficient $\varphi$. Finally, it is important to note that discretization in characteristic points of the capacity curve makes easy the comparison capacity-demand and already shows inclination towards the generality of the application of the method, being associated with behavioural characteristics of structures that are independent of the structural type. 


\section{ACKNOWLEDGEMENTS}

The research leading to the results presented in this paper has received funding from the Italian Department of Civil Protection (DPC-Reluis). The support of DPC-RELUIS 2019-2021 is gratefully acknowledged.

\section{REFERENCES}

[1] H.-C. Jung, J.-S. Jung, K.S. Lee "Seismic performance evaluation of internal steel frame connection method for seismic strengthening by cycling load test and nonlinear analysis" (2019) Journal of the Korea Concrete Institute, 31 (1), pp. 79-88.

[2] R. Montuori, E. Nastri, V. Piluso, P. Todisco, “A simplified performance based approach for the evaluation of seismic performances of steel frames", Engineering Structures, 224, art. no. 111222, (2020).

[3] R. Montuori, E. Nastri, V. Piluso, P. Todisco, "Evaluation of the seismic capacity of existing moment resisting frames by a simplified approach: Examples and numerical application" (2021) Applied Sciences (Switzerland), 11(6), art. no. 2594.

[4] R. Montuori, E. Nastri, V. Piluso, "Problems of modeling for the analysis of the seismic vulnerability of existing buildings" (2019) Ingegneria Sismica, 36 (2), pp. 53-85.

[5] F. Barbagallo, M. Bosco, A. Floridia, E.M. Marino, P.P. Rossi, "Design for seismic upgrading of existing RC frames by friction dampers", (2020) Ingegneria Sismica, 37 (1), pp. 5-18.

[6] M. Ferraioli, A. Lavino, A. Mandara, "Seismic retrofit design method of RC buildings using metallic yielding dampers" (2020) Ingegneria Sismica, 37 (1), pp. 19-32.

[7] M. Ferraioli, A. Lavino, A. Mandara, "Effectiveness of multi-mode pushover analysis procedure for the estimation of seismic demands of steel moment frames" (2018) Ingegneria Sismica, 35 (2), pp. 78-90.

[8] C. Bernuzzi, D. Rodigari, M. Simoncelli, "Post-earthquake damage assessment of moment resisting steel frames" (2019) Ingegneria Sismica, 36 (4), pp. 35-55.

[9] D. De Domenico, N. Impollonia, G. Ricciardi, "Seismic retrofitting of confined masonryRC buildings: The case study of the university hall of residence in Messina, Italy" (2019) Ingegneria Sismica, 36 (1), pp. 54-85.

[10] E. Nastri, M. Vergato, M. Latour, "Performance evaluation of a seismic retrofitted R.C. precast industrial building" (2017) Earthquake and Structures, 12 (1), pp. 13-21.

[11] S. Wang, J.-W. Lai, M.J. Schoettler, S.A. Mahin, "Seismic assessment of existing tall buildings: A case study of a 35-story steel building with pre-Northridge connection" (2017) Engineering Structures, 141, pp. 624-633.

[12] S. Costanzo, M. D'Aniello, R. Landolfo, Proposal of design rules for ductile X-CBFS in the framework of EUROCODE 8. Earthquake Engng Struct Dyn. Volume 48, Issue 1, Pages 124-151, January 2019. https://doi.org/10.1002/eqe.3128

[13] R. Tartaglia, M. D’Aniello, G.A. Rassati, (2019) Proposal of AISC-compliant seismic design criteria for ductile partially-restrained end-plate bolted joints. Journal of Constructional Steel Research Volume 159, August 2019, Pages 364-383 
[14] D. Vamvatsikos, K. Bakalis, M. Kohrangi, S. Pyrza, C. Castiglioni, A. Kanyilmaz, F. Morelli, A. Stratan, M. D' Aniello, L. Calado, J.M. Proença, H. Degee, B. Hoffmeister, M. Pinkawa, P. Thanopoulos, I. Vayas, (2020). A risk-consistent approach to determine EN1998 behaviour factors for lateral load resisting systems. Soil Dynamics and Earthquake Engineering 131, 106008

[15] S. Shakeel, L. Fiorino, R. Landolfo, Behavior factor evaluation of CFS wood sheathed shear walls according to FEMA P695 for Eurocodes. Engineering Structures, 2020, 221, 111042

[16] L. Fiorino, S. Shakeel, R. Landolfo, Seismic behaviour of a bracing system for LWS suspended ceilings: Preliminary experimental evaluation through cyclic tests. ThinWalled Structures, 2020, 155, 106956

[17] A. Campiche, L. Fiorino, R. Landolfo, Numerical modelling of CFS two-storey sheathing-braced building under shaking-table excitations. Journal of Constructional Steel Research, 2020, 170, 106110

[18] A. Campiche, Numerical modelling of cfs three-story strap-braced building under shaking-table excitations. Materials, 2021, 14(1), pp. 1-13, 118

[19] A. Poursadrollah, M. D’Aniello, R. Landolfo, A. De Martino (2020), "Preliminary Study on The Seismic Performance of Hybrid Steel Structures with Truss Lightweight Girders and Plug-and-Play Connections" (2020) Ingegneria Sismica: International Journal of Earthquake Engineering, 37(1), pp. 103-113.

[20] Costanzo S, D'Aniello M, Landolfo R. Seismic design rules for ductile Eurocode compliant two storey X concentrically braced frames. Steel and Composite Structures, Vol. 36, No. 3 (2020) 273-291. DOI: https://doi.org/10.12989/scs.2020.36.3.273

[21] S. Costanzo, M. D’Aniello, R. Landolfo, (2017). Seismic Design Criteria for Chevron CBFs: European vs North American Codes (PART-1). Journal of Constructional Steel Research, Volume 135, August 2017, Pages 83-96. 10.1016/j.jcsr.2017.04.018

[22] M. Bruneau, C.M. Uang, R.S.E. Sabelli, (2011). Ductile Design of Steel Structures. McGraw-Hill.

[23] S. Costanzo, M. D’Aniello, R. Landolfo, A. De Martino, (2018). Critical discussion on seismic design criteria for $\mathrm{X}$ concentrically braced frames. Ingegneria Sismica: International Journal of Earthquake Engineering, Volume 35, Issue 2, 2018, Pages 23-36.

[24] S.-H. Hwang, J.-S. Jeon, K. Lee, "Evaluation of economic losses and collapse safety of steel moment frame buildings designed for risk categories II and IV" (2019) Engineering Structures, 201, art. no. 10983.

[25] E. Romano, L. Cascini, M. D’Aniello, F. Portioli, R. Landolfo, (2020) simplified multiperformance approach to life-cycle assessment of steel structures. Structures 27 (2020) $371-382$

[26] A. Gupta, H. Krawinkler, "Feasibility of push-over analyses for estimation of strength demand", Stessa 2003, - Behaviour of Steel Structures in Seismic Areas: Proceedings of the 4th International Specialty Conference, Naples, Italy, 9-12 June 2003.

[27] NTC 2018 Italian Code: Chapter 7 "Design for seismic actions".

[28] P. Fajfar, “A Nonlinear Analysis Method for Performance-Based Seismic Design,” Earthq. Spectra, 2000. 
[29] FEMA, "Seismic performance assessment of buildings. Volume 1- Methodology," Fema P-58-1, 2012

[30] A. Gupta and H. Krawinkler, "Seismic Demands for Performance Evaluation of Steel Moment Resisting Frame Structures," (1999).

[31] D. Cassiano, M. D'Aniello, C. Rebelo, (2017) Parametric finite element analyses on flush end-plate joints under column removal. Journal of Constructional Steel Research, Volume 137, October 2017, Pages 77-92

[32] R. Tartaglia, M. D'Aniello, M. Zimbru, R. Landolfo, (2018). Finite element simulations on the ultimate response of extended stiffened end-plate joints. Steel and Composite Structures, An International Journal Vol. 27 No. 6, June25 2018. pages 727-745. DOI: 10.12989/scs.2018.27.6.727

[33] S. Costanzo, M. D'Aniello, R. Landolfo (2018). The influence of moment resisting beamto-column connections on seismic behavior of chevron concentrically braced frames. Soil Dynamics and Earthquake Engineering 113 (2018) 136-147

[34] R. Tartaglia, M. D'Aniello, R. Landolfo, (2018). The influence of rib stiffeners on the response of extended end-plate joints. Journal of Constructional Steel Research 148 (2018) 669-690.

[35] M. D'Aniello, R. Tartaglia, D. Cassiano, (2020) Experimental Investigation of The Inelastic Tensile Behaviour of Non-Preloadable Grade 8.8 Bolts. Ingegneria Sismica: International Journal of Earthquake Engineering, Volume 37, Issue 2, 2020, Pages 92-110

[36] R. Tartaglia, M. D'Aniello, M. Zimbru, (2020). Experimental and numerical study on the T-Stub behaviour with preloaded bolts under large Deformations. Structures Volume 27, October 2020, Pages 2137-2155 https://doi.org/10.1016/j.istruc.2020.08.039

[37] M. Pongiglione, C. Calderini, M. D’Aniello, R. Landolfo, Novel Reversible Seismic-Resistant Joint for Sustainable and Deconstructable Steel Structures, Journal of Building Engineering, 2021, 35, 101989 https://doi.org/10.1016/j.jobe.2020.101989

[38] R. Tartaglia, M. D’Aniello, R. Landolfo, (2020). Numerical Simulations to Predict the Seismic Performance of a 2-Story Steel Moment-Resisting Frame. Materials 2020, 13(21), 4831; doi:10.3390/ma13214831

[39] R. Montuori, E. Nastri, P.Todisco, "Influence of the seismic shear proportioning factor on steel MRFs seismic performances", Soil Dynamics and Earthquake Engineering, 2020, 106498, ISSN 0267-7261, https://doi.org/10.1016/j.soildyn.2020.106498.

[40] R. Montuori, G. Gabbianelli, E. Nastri, M. Simoncelli, "Rigid plastic analysis for the seismic performance evaluation of steel storage racks" (2019) Steel and Composite Structures, 32 (1), pp. 1-19.

[41] R. Montuori, E. Nastri, V. Piluso, "Advances in theory of plastic mechanism control: Closed form solution for MR-Frames", (2015) Earthquake Engineering and Structural Dynamics, 44 (7), pp. 1035-1054.

[42] E. Nastri, M. D'Aniello, M. Zimbru, S. Streppone, R. Landolfo, R. Montuori, V. Piluso, "Seismic response of steel Moment Resisting Frames equipped with friction beam-tocolumn joints", Soil Dynamics and Earthquake Engineering, 119, 144-157, (2019). 
[43] G. Dell'Aglio, R. Montuori, E. Nastri, V. Piluso, "Consideration of second-order effects on plastic design of steel moment resisting frames" Bulletin of Earthquake Engineering, 17 (6), pp. 3041-3070, (2019).

[44] V. Piluso, R. Montuori, E. Nastri, A. Paciello, "Seismic response of MRF-CBF dual systems equipped with low damage friction connections", Journal of Constructional Steel Research, 154, pp. 263-277, (2019).

[45] S. Krishnan, M. Muto, "Mechanism of collapse of Tall Steel Moment-Frame Buildings under Earthquake Excitation", Journal of Structural Engineering, ASCE, November 2012, 138: 1361-1387.

[46] A. Pisapia, E. Nastri, Probabilistic theory of plastic mechanism control: Design and seismic assessment (2019) COMPDYN Proceedings, 3, pp. 4201-4212.

[47] E. Nastri, P. Tsarpalis, Seismic analyses of dual concentrically braced frames accounting for the presence of haunched connections (2019) COMPDYN Proceedings, 1, pp. 73-95.

[48] A. Catapano, E. Nastri, S. Streppone, Design and analysis of dual EBFs equipped with prequalified connections (2019) COMPDYN Proceedings, 1, pp. 96-130.

[49] E. Nastri, "The influence of geometry, loads and steel grade for the development of a specific collapse type of MR-Frames" (2017) COMPDYN 2017 - Proceedings of the 6th International Conference on Computational Methods in Structural Dynamics and Earthquake Engineering, 2, pp. 5014-5025.

[50] E. Nastri, "Eccentrically braced frames designed for the energy dissipation optimization", (2016) ECCOMAS Congress 2016 - Proceedings of the 7th European Congress on Computational Methods in Applied Sciences and Engineering, 4, pp. 8476-8491.

[51] V. Piluso, A. Pisapia, P. Castaldo, E. Nastri, "Probabilistic Theory of Plastic Mechanism Control for Steel Moment Resisting Frames”, (2019) Structural Safety, 76, pp. 95-107.

[52] M. J. N. Priestley, "Performance based seismic design" Bull. New Zeal. Soc. Earthq. Eng., 2000 .

[53] Eurocode 8 (2004). EN 1998-1: Design of Structures for Earthquake Resistance - Part 1: general Rules, Seismic Actions and Rules for Buildings, CEN.

[54] Eurocode 3 (2005). UNI EN 1993-1-1: Design of steel structures Part 1-1: General rules and rules for buildings, CEN.

[55] R. Montuori, E. Nastri, B. Tagliafierro, “An optimal seismic force pattern for uniform drift distribution” (2019) Buildings, 9 (11), art. no. 231.

[56] F.M. Mazzolani, V. Piluso, (1997). Plastic Design of Seismic Resistant Steel Frames. Earthquake Engineering and Structural Dynamics, 26, 167-191.

[57] F.M. Mazzolani, V. Piluso, (1996). Theory and Design of Seismic Resistant Steel Frames. E\&FN Spon, London.

[58] D. Grecea, F. Dinu, D. Dubina, "Performance Criteria for MR Steel Frames in Seismic Zones", Journal of Constructional Steel Research, 60, 739-749, 2004.

[59] N. Newmark, \& W. Hall (1982). Earthquake Spectra and Design. In EERI Monographs.

[60] Eurocode 8 (2004). EN 1998-3: Design of Structures for Earthquake Resistance - Part 3: Assessment and retrofitting of buildings, CEN. 
[61] F. Naeim, "Earthquake Engineering-From Engineering Seismology to PerformanceBased Engineering", Earthq. Spectra, 2005. 